Research, part of a Special Feature on Mental Models

\title{
Mental Models: An Interdisciplinary Synthesis of Theory and Methods
}

\author{
$\underline{\text { Natalie A. Jones }}^{1}, \underline{\text { Helen Ross }}^{1}, \underline{\text { Timothy Lynam }}^{2}{ }^{\text {Pascal Perez }}{ }^{3,4}$, and $\underline{\text { Anne Leitch }}^{2,5}$
}

\begin{abstract}
Mental models are personal, internal representations of external reality that people use to interact with the world around them. They are constructed by individuals based on their unique life experiences, perceptions, and understandings of the world. Mental models are used to reason and make decisions and can be the basis of individual behaviors. They provide the mechanism through which new information is filtered and stored. Recognizing and dealing with the plurality of stakeholder's perceptions, values, and goals is currently considered a key aspect of effective natural resource management (NRM) practice. Therefore, gaining a better understanding of how mental models internally represent complex, dynamic systems and how these representations change over time will allow us to develop mechanisms to enhance effective management and use of natural resources. Realizing this potential, however, relies on developing and testing adequate tools and techniques to elicit these internal representations of the world effectively. This paper provides an interdisciplinary synthesis of the literature that has contributed to the theoretical development and practical application of the mental model construct. It explores the utility and applicability of the construct in the context of NRM and includes a review of elicitation techniques used within the field. The major theoretical and practical challenges that arise in drawing on the construct to provide a cognitive dimension to NRM are also addressed.
\end{abstract}

Key Words: cognition; elicitation; mental model; natural resource management

\section{INTRODUCTION}

Gaining insight into those aspects of human cognition that underpin preferences, action, and behavior is of great value to the field of natural resource management (NRM). Environmental problems are largely driven by human decisions and actions, as are the strategies designed to address such problems. In the past, NRM researchers have attempted to understand behavior by focusing on stakeholders' attitudes, preferences, and values. These social science constructs, while providing important insights, fail to account for the human capacity to predict outcomes or analyze cause-effect relationships and hence frame their selection of responses.

It is widely accepted in the cognitive science and psychology literature that people develop and use internal representations, i.e., 'mental models', of external reality that allow them to interact with the world (Craik 1943, Johnson-Laird 1983). People must know about their environment so they can exist within it (Moore and Golledge 1976). Mental models are conceived of as a cognitive structure that forms the basis of reasoning, decision making, and, with the limitations also observed in the attitudes literature, behavior. They are constructed by individuals based on their personal life experiences, perceptions, and understandings of the world. They provide the mechanism through which new information is filtered and stored.

Peoples' ability to represent the world accurately, however, is always limited and unique to each individual. Mental models are therefore characterized as incomplete representations of reality. They are also regarded as inconsistent representations because they are context-dependant and may change according to the situation in which they are used. In essence, mental models have to be highly dynamical models to adapt to continually changing circumstances and to evolve over time through learning. Conceptualizing cognitive representations 
as dynamic, inaccurate models of complex systems acknowledges the limitations in peoples' ability to conceive such complex systems.

Mental models exist within the mind and are therefore not available for direct inspection or measurement. Finding ways of eliciting a mental model presents a major challenge to any discipline interested in using the construct as a means to gain insight into people's internal representations of the world. A variety of elicitation tools and techniques have been developed and used in different fields of applied research, including organizational research (Hall et al. 1994, Swan and Newell 1998, Sterman 2000), risk communication (Breakwell 2001, Morgan et al. 2002, Hodgkinson et al. 2004, Lowe and Lorenzoni 2007), human-computer interaction (Cooke 1999), and education (Osborne and Cosgrove 1983, Vosniaudou and Brewer 1992, Samarapungavan et al. 1996, Dove et al. 1999).

To understand the role of mental models in NRM we need to know what they are and how they have been conceptualized in different disciplines. We provide theoretical background to the empirical analysis of the papers in this issue by presenting an interdisciplinary synthesis of the mental model literature. The paper defines mental models and shows how the construct is used across disciplines. It discusses the potential contribution of the mental model construct to the field of NRM, and the major challenges that must be addressed to realize this potential.

\section{WHAT IS A MENTAL MODEL ?}

\section{A cognitive representation}

Mental models are cognitive representations of external reality. The notion of a mental model was originally postulated by the psychologist Kenneth Craik (1943) who proposed that people carry in their minds a small-scale model of how the world works. These models are used to anticipate events, reason, and form explanations. Decades later, psychologist Johnson-Laird (1983) further developed Craik's idea of a mental model in his research on human reasoning. For Johnson-Laird, a mental model is a reasoning mechanism that exists in a person's working memory. His research, carried out within the domain of experimental psychology, supports
Craik's claim that people reason by way of thought experiments using internal models.

Another major body of research that draws on the mental model construct is known as 'naive theory', also referred to as 'naive physics'. Research explores how people develop an understanding of causal processes associated with physical or mechanical systems. Studies have led theorists to assert that mental models are formed through analogical thinking. According to Collins and Gentner (1987), when a person explains a domain with which they are unfamiliar, they tend to draw on a familiar domain, which they perceive as similar. This involves tapping into an existing mental model and importing its relational structure to another domain. For example, a mental model of water flow may be used to explain electrical current; entities and relations corresponding to the former are mapped on to the model representing the latter. Studies show that phenomena that cannot be perceived directly are often explained this way (Rickheit and Sichelschmidt 1999).

Gentner and Gentner (1983) and Collins and Gentner (1987) questioned whether people use analogies as a convenient way of talking about another domain or whether they actually think in analogies. Experimental studies examining peoples explanations of electricity (Gentner and Gentner 1983) and water molecules (Collins and Gentner 1987) provide evidence in support of the idea that people do indeed use analogies in their cognitive processes. Analogical thinking allows people to "create new mental models that they can then run to generate predictions about what should happen in various situations in the real world" (Collins and Gentner 1987:243). Mental models thus act as inferential frameworks (Gentner and Gentner 1983), as originally posed by Craik.

Abel et al. (1998), in acknowledging that theory on cognitive mapping originated from spatial cognition studies, conceptualize a cognitive map as a 'spatial mental model'. 'Cognitive mapping' is the process through which a person acquires, stores, codes, and recalls information about the world. Like Craik's notion of a mental model, the process of cognitive mapping provides a reasoning and predictive capacity: it "enables people to generalize on the basis of past experiences and to use these generalizations (or generic information) in other 
contexts" (Downs 1976:69). However, reasoning and prediction processes are carried out via associations and networks of mental objects, often referred to as 'schema', rather than qualitative thought experiments using symbolic models, as proposed by Craik and Johnson-Laird.

Although the literature shows consensus on the point that mental models are typically analogous representations, a discrepancy exists over where in the mind mental models are hypothetically located: working memory (Johnson-Laird 1983, Wilson and Rutherford 1989, Vosniaudou 1994), long-term memory (Craik 1943, Bainbridge 1991, Moray 2004), or both (Nersessian 2002). Johnson-Laird has provided tangible evidence supporting the idea that mental models are temporary structures that occupy working memory, based on psychological experiments involving simple, static phenomena. $\mathrm{He}$ agrees, however, that a mental model can represent either long-term or short-term knowledge (1989) and can represent physical or conceptual entities (Johnson-Laird 1983).

Those who conceptualize mental models as residing in long-term memory, i.e., mainly naive theory and systems researchers, view them as long-term knowledge structures that 'support' reasoning and understanding (Nersessian 2002). In that sense, mental models are similar to the 'schema' construct. Originally introduced by Bartlett (1932), schema are conceived of as long-term knowledge structures which people use to interpret and make predictions about the world around them. In the early 1980s, Johnson-Laird (1983) stated that the difference between schemata and mental models is yet to be resolved, others have since differentiated between the concepts (Table 1).

Nersessian (2002) bridges the working memory vs. long-term memory discrepancy by stating that mental models that exist as knowledge structures in long-term memory are called upon to support the mental models formed in working memory that are used to support reasoning and problem-solving. Conceiving a mental model as a cognitive structure that may exist in either working memory or longterm memory is reminiscent of Argyris and Schon's (1974) 'theories of action'. They suggest that what people say, the 'espoused theory', is different than what they do, the 'theory in use'. Asking someone about their thoughts or beliefs on an issue elicits an espoused theory that can be equated with a mental model generated in working memory for the purpose of answering a specific question (following Brewer's definition noted above). This involves drawing on existing, deeply held, generic knowledge to compile a specific knowledge structure to answer a given question. Drawing on long-term knowledge structures and combining them in short-term memory involves a degree of abstraction. This is therefore likely to increase the degree of representational inaccuracy in the generated mental model, or espoused theory. According to Argyris and Schon (1974), when someone 'acts' they rely on tacit knowledge structures, what is referred to as the 'theory in use', which may be equated with mental models existing in long-term memory. Although these internal representations of the world may be less error prone, Argyris and Schon's work suggests they are much more difficult to elicit. This highlights one of the key challenges associated with applying the mental model construct, not only to NRM, but all disciplines interested in the theoretical and practical application of the construct. That is, how can we differentiate and elicit the mental models that people rely on to make decisions and act, rather than the mental models which equate with Argyris and Schon's 'espoused theory'?

Mental models stored in long-term memory are also of particular interest to the field of cognitive anthropology, which explores "how cultural knowledge is organized in the mind" (D'Andrade 1995:279) . Studying culture at a cognitive level, cognitive anthropologists use schema to explain cultural understanding. Quinn (2005:38) defines schema as "a generic version of (some part of) the world built up from experience and stored in memory". 'Cultural schema' are therefore developed through "shared" experiences (Quinn 2005:38). Over time, as a given group of people internalize their shared experiences, cultural meaning is created, which individuals use to perceive and relate to the world around them (Quinn 2005).

Cultural models are discussed in a similar light to collective mental models and shared mental models in that they all refer to a degree of shared understanding among a group people. The field of organizational research takes a keen interest in collective mental models on the assumption that "effective team functioning requires the existence of a shared or team mental model among members of a team" (Langan-Fox et al. 2000:242). It is interesting to note that some of this literature uses 
Table 1. Differences between mental models and schemata.

\begin{tabular}{|c|c|c|c|}
\hline Author & Basis of Differentiation & Schemata & Mental Models \\
\hline $\begin{array}{l}\text { Rutherford and Wilson } \\
(2004: 312)\end{array}$ & $\begin{array}{l}\text { Static vs. dynamic } \\
\text { structure }\end{array}$ & $\begin{array}{c}\text { "...A procedural data structure in } \\
\text { memory". }\end{array}$ & $\begin{array}{l}\text { Use procedural data "in a } \\
\text { computationally dynamic } \\
\text { manner". }\end{array}$ \\
\hline Holland et al. (1986:13) & $\begin{array}{l}\text { Representational } \\
\text { flexibility }\end{array}$ & $\begin{array}{l}\text { Inflexible knowledge structures } \\
\text { stored in long-term memory } \\
\text { provide "predictive knowledge } \\
\text { for highly regular and routine } \\
\text { situations". }\end{array}$ & $\begin{array}{l}\text { Flexible knowledge structure that } \\
\text { combines multiple schemata to } \\
\text { represent or simulate an } \\
\text { unfamiliar situation. }\end{array}$ \\
\hline Brewer (1987:189) & $\begin{array}{l}\text { Generic vs. specific } \\
\text { knowledge }\end{array}$ & $\begin{array}{l}\text { “...Precompiled generic } \\
\text { knowledge structures.” }\end{array}$ & $\begin{array}{l}\text { "Specific knowledge structures } \\
\text { that are constructed to represent a } \\
\text { new situation through the use of } \\
\text { generic knowledge of space, time, } \\
\text { causality, and human } \\
\text { intentionality". }\end{array}$ \\
\hline
\end{tabular}

the terms 'shared' and 'team' mental models interchangeably (e.g., Klimoski and Mohammed 1994), however, the two are usually defined as distinct constructs. A shared mental model is the mental model constructed and shared when individuals interact together in a team setting, it represents the shared cognition among groups of individuals (Langan-Fox et al. 2001). A team model is the collective task and team relevant knowledge that team members bring to a situation (Cooke et al. 2000). The team's collective and dynamic understanding that they bring to a specific situation is referred to as a team situation model (Cooke et al. 2000).

Practitioners in the field of NRM have also recently taken an interest in the idea of the collective or shared mental model (Abel et al. 1998). To encourage people with contrasting views to work together, it is necessary to identify and support a shared understanding among relevant stakeholders and to enhance the collective decision making process. The expansion of mental models research from an individual to a collective focus stems from a growing recognition that there is a social component to cognition at the individual level, and that decision making occurs at a range of scales from an individual to group to societal level.

\section{A dynamic representation}

There is widespread agreement in the literature that mental models are 'working models' (Craik 1943, Johnson-Laird 1983) and are therefore dynamic. The dynamic character of a mental model is discussed in the literature in three ways, in relation to reasoning, causal dynamics, and learning.

\section{Reasoning}

A defining feature of a mental model from a psychology perspective is that it is a computational structure (Rutherford and Wilson 2004). A mental model is constructed in working memory and can then be run like a computer simulation allowing an individual to explore and test different possibilities mentally before acting. Working memory is the system responsible for selecting and manipulating information for the purpose of reasoning and learning. Changes made to a mental model in the simulation process represent what would happen if such changes took place in reality.

\section{Causal dynamics}

The second dynamic attribute of a mental model discussed at length in the literature refers to "causal knowledge'. The capacity of a mental model to 
represent (perceived) cause-and-effect dynamics of a phenomenon is studied from a systems dynamics and naive theory perspective. Researchers interested in systems dynamics use the mental model construct in a pragmatic sense: as a tool to better understand complex, dynamic systems to ultimately improve their design and usability (Doyle and Ford 1998, Moray 2004). A widely cited definition of a mental model in this context is that of Rouse and Morris (1986) who consider a mental model in terms of its functionality and conceive it as a cognitive structure that enables a person to describe, explain, and predict a system's purpose, form, function, and state. Given the focus on dynamic phenomena, a mental model in this field has been conceived of as a model that is built of "causal knowledge about how a system works" (Moray 1998:295).

\section{Learning}

The capacity of mental models to change over time through experience and learning is another dynamic quality often referred to in the literature. Researchers, mainly from the fields of humancomputer interaction (HCI), education, and organizational studies, take interest in the difference between lay (or student) and expert mental models in terms of knowledge content and organization. Research shows that lay understanding is characteristically concrete while expert understanding is more abstract (DiSessa 1983, Greeno 1983, Larkin 1983). This highlights the idea that the formation of a mental model in a person's mind is the result of both biology, i.e., an ability inherent to the human mind, and 'learning' (Nersessian 2002). Nersessian (2002:140) states that, "the nature and richness of models one can construct and one's ability to reason develops with learning domainspecific content and techniques".

Systems dynamics researchers focus on the role of mental models in information feedback loops. They are particularly interested in the problems which hinder information feedback in a system and therefore hinder learning (Doerner 1980, Brehmer 1992).

\section{An inaccurate and incomplete representation}

Mental models tend to be functional rather than complete or accurate representations of reality. A mental model is a simplified representation of reality that allows people to interact with the world. Because of cognitive limitations, it is neither possible nor desirable to represent every detail that may be found in reality. Aspects that are represented are influenced by a person's goals and motives for constructing the mental model as well as their background knowledge or existing knowledge structures, which, as noted above, may be conceptualized as 'mental models existing in long term memory'. Mental models thus play a role in filtering incoming information. The theory of 'confirmation bias' (Klayman and $\mathrm{Ha}$ 1989) suggests that people seek information that fits their current understanding of the world. Incoming information may reinforce existing mental models or may be rejected outright.

Different fields of study are interested in, and therefore view, the inaccurate and incomplete quality of mental models differently. Those applying the mental model construct to complex systems regard the mapping process involved in constructing a mental model as a many-to-one 'homo-morphic' mapping. This involves decomposing a complex system into a number of smaller models representing subcomponents of the system. Conceiving the construction of mental models in this way suggests that the model is an "imperfect representation" and acknowledges that people make errors (Moray 2004). Similarly, systems dynamics researchers draw attention to peoples' cognitive limitations in terms of processing information feedback, particularly when there are long time delays between action and response (Sterman 1994). Controlled experiments, mainly computerbased, show that people's mental models demonstrate a limited capacity to take account of feedback delays and the side effects of decisions made (Doerner 1980, Brehmer 1992). In his study of mental models, Sterman (1994:305) concluded that "people generally adopt an event-based, openloop view of causality, ignore feedback processes, fail to appreciate time delays between action and response and in the reporting of information, and are insensitive to non-linearities that may alter the strengths of different feedback loops as a system evolves". This literature treats these limitations in people's mental models as presenting an impediment to learning; it assumes that addressing the limitations and critical flaws in mental models can improve system functionality.

Despite their potential limitations, individuals' mental models are not necessarily amenable to 
alteration. As the psychology literature recognizes, people tend to filter new information according to its congruence or otherwise with their existing understandings, beliefs, and values. They may reject discrepant evidence, or compartmentalize it within a subsystem of larger systems of understanding. Acceptance of new information is also related to personal orientations toward learning. Some mental models research therefore focuses on communication toward outcomes such as behavior change, seeking to provide information in forms compatible with current understandings (Morgan et al. 2002).

\section{MENTAL MODEL ELICITATION IN NATURAL RESOURCE MANAGEMENT}

Interest in mental models is gaining momentum within the domain of NRM as practitioners increasingly recognize the need to take into account the plurality of values and goals linked to a given resource and the range of stakeholder perceptions concerning how NRM systems function. Mental models are elicited for the following reasons:

- To explore similarities and differences between stakeholders' understanding of an issue to improve communication between stakeholders (Abel et al. 1998) ;

- To integrate different perspectives, including expert and local, to improve overall understanding of a system (Ozesmi and Ozesmi 2004);

- To create a collective representation of a system to improve decision making processes (Dray et al. 2006);

- To support social learning processes (PahlWostl and Hare 2004);

- To identify and overcome stakeholders' knowledge limitations and misconceptions associated with a given resource (Morgan et al. 2002);

- To develop more socially robust knowledge to support negotiations over unstructured problems in complex, multifunctional systems (Kolkman et al. 2005).

The mental model construct is attractive to NRM practitioners in that it takes account of the concepts that stakeholders consider relevant or important to a domain, and of the way in which stakeholders structure or organize those concepts cognitively. This provides insight into stakeholders' understanding of the interconnected and dynamic attributes of NRM systems. Biggs et al. (2008:3) situate the construct within the field of NRM by defining it as a cognitive structure comprised of "representations of objects, their relationships and dynamics as well as the attributes or characteristics of these and the person's valence (cognitive and emotional) to the objects, relationships, and dynamics".

A variety of elicitation techniques have been used in the field of natural resource management to serve different purposes. The majority of procedures used are based on the assumption that an individual's mental model can be represented as a network of concepts and relations. Some procedures are designed to elicit a network representation of a mental model directly from the interviewee through a diagrammatic interview. Other procedures require the researcher to re-create, or infer, the network from oral interview data or questionnaire data.

\section{Direct elicitation}

Direct elicitation procedures require interviewees to form a representation of their understanding of a given issue. Participants may be asked to draw a diagrammatic representation of their mental model, using pictures, words, and symbols, or they may be provided with existing concepts on a set of cards and asked to arrange them into a representation. Assisting participants to view the external representation of their mental model through the nature of the elicitation process provides an immediate means of verification that is lacking in the indirect elicitation procedures.

Kearney and Kaplan propose the Conceptual Content Cognitive Map (3CM) method (originally developed by Austin, cited in Kearney and Kaplan 1997). This technique involves asking participants to identify concepts they consider important to a domain and then asking them to spatially/visually organize them in a way that depicts how they understand that domain (see Kearney and Kaplan 1997). The spatial mapping exercise is believed to be highly compatible with human information processing (Pezdek and Evans, as cited in Kearney and Kaplan 1997). A major strength of the approach is that the mapping exercise assists interviewees to explore their own cognitive structure as they engage 
with the task (Austin 1994). This stance is supported by studies that suggest cognition is not only language-based but also image-based and that verbal and imagistic thought are carried out by two distinct, though partly connected, systems (Kearney and Kaplan 1997:595). The 3CM technique has been used in the field of NRM to explore the nature of different stakeholders' perspectives in the context of forest management (Austin 1994, Kearney et al. 1999, Tikkanen et al. 2006). Analysis involves a combination of qualitative and quantitative procedures to determine the similarity and dissimilarity in stakeholder's views.

Ozesmi and Ozesmi (2004) used a similar approach, referred to as fuzzy cognitive mapping, to explore stakeholders' perceptions of the causes and effects of lake eutrophication. Similarly to Kearney and Kaplan's 3CM approach, Ozesmi and Ozesmi elicit mental models by asking interviewees to begin by defining the important variables in a given system. These are written on a set of cards. Participants are then given the opportunity to arrange the cards to reflect their understanding of a given issue. Ozesmi and Ozesmi's approach is designed to elicit an interviewee's causal understanding of a system and thus targets the cause and effect relationships between concepts. Participants are asked to specify these relationships in the constructed diagram. Graph theory tools that apply mathematical algorithms are then used to explore the complexity of the network diagrams, their density, i.e., how connected or sparse they are, as well as the type and frequency of variables featured. Ozesmi and Ozesmi (2004) state that "By examining the structure of maps we can determine how stakeholders view the system, for example whether they perceive a lot of forcing functions affecting the system which are out of their control, or whether they see the system as hierarchical or more democratic" (Ozesmi and Ozesmi 2004:50). According to Ozesmi and Ozesmi (2004:50), "If some groups perceive more relationships, they will have more options available to change things. Thus these groups may be a catalyst for change". It is important to note that this does not mean that a greater understanding of how a system functions equates with a greater capacity to initiate change because other factors come into play including the social, political, and economic context. The authors suggest that a more comprehensive understanding of a given system means a wider range of interventions can be explored. Data representing peoples' mental models of cause and effect relations within a system can be used to build computer simulation models that explore different resource management scenarios. Local stakeholders thus play a key role in building the models that guide resource management policy and planning. Ozesmi and Ozesmi (2004) state that this form of participatory modeling is preferable to other forms of science-based ecological modeling in situations where 1) expert and scientific data is limited, whether it be uncertain and/or unavailable, and 2) stakeholder support for management initiatives is required.

Dray et al. (2006) used a similar diagrammatic interview method to elicit understanding of causal dynamics of groundwater management in the atoll of Tarawa, Republic of Kiribati. This experiment involved asking participants to build a diagram by placing cards indicating relevant concepts (factors or dynamics) on a large piece of paper and drawing the relations between them. The data was combined with data collected from a photo interpretation and a spatial mapping exercise, to build a 'collective representation' of the groundwater system. This provided the basis upon which an agent-based model and role playing game were designed that were used as negotiation and decision making support tools in the context of groundwater management. Through interacting with these tools, participants were able to explore and challenge their own and others' mental models (Dray et al. 2007).

Participatory modeling initiatives relying on mental model elicitation techniques to build a collective representation, or 'shared mental model', of a given system have also been used in a number of resource management projects to support collective decision making (Lynam et al. 2002) and social learning processes (Pahl-Wostl and Hare 2004). The Actors, Resources, Dynamics and Interaction (ARDI) method is one such method used for this purpose (Etienne et al. 2011, Mathevet et al. 2011). It involves systematically asking participants, either individually or as a group, who and what they consider to be the key actors, resources, and processes, or dynamics, within a system and the interactions between these. This exercise creates a representation of an individual or group mental model of the system in the form of an influence diagram that can be used to guide the development of a resource management plan or used as a dialogue support tool. 


\section{Indirect elicitation}

Carley and Palmquist (1992) propose that a representation of a mental model, made up of concepts and relations, can be extracted from written documents or verbal text, which may be elicited via an interview. The verbal structure identified within a text is a sample of the full symbolic representation of an individual's cognitive structure (Carley, Fauconnier, and Sowa, as cited in Carley and Palmquist 1992).

Abel et al. (1998) used the transect walk method involving a combination of open-ended and semistructured interview questions while walking an area to elicit people's understanding of causal dynamics of landscape processes. The aims of this study were to develop a methodology to elicit mental models of landscape systems, and to explore similarities and differences in stakeholder groups' understanding in the context of land management. The study was motivated by an acknowledgment that differences in understanding hinder communication and cooperation between stakeholders and therefore impede management efforts. Interview data from pastoralists, extension officers, and research scientists was analyzed using content analysis then statistical analysis to identify and compare differences between interviewees in emphasis on landscape characteristics and ecological processes, and the causal linkages between these. Direct causal connections between landscape variables were recorded in a matrix. The matrix data was then converted into an influence diagram, also referred to as a 'causal network diagram', using Vensim, a simulation and decision support package, then the INFLUENCE program (Walker 1997). The resulting diagrams were taken as representing stakeholders' mental models of the causal dynamics of the system. The authors remind us, however, that these representations of mental models are influenced by the skill of the interviewer and the extent to which the interviewee is able to verbalize his or her understanding of causal dynamics. This capacity is likely to differ across individuals and groups, with researchers and extension officers presumably more versed in communicating their ideas in such a context (Abel et al. 1998).

One approach to mental model elicitation that does not seek to represent a mental model as a network of concepts and relations is consensus analysis (discussed in greater detail in Stone-Jovicich et al. 2011). This approach, originating in the field of cognitive anthropology, is designed to investigate the distribution of cultural knowledge among a given group of people. Cultural knowledge is conceived of as an 'information pool' that is held within the minds of individuals. It is assumed that there is variability in the amount of information held by each individual and the extent to which this information is shared. The consensus analysis literature refers to the part of the information pool that each individual holds within their mind as 'schema'. These are defined as "networks of strongly connected cognitive elements that represent the generic concepts stored in memory" (Strauss and Quinn 1997:6) and thus can be thought of as mental models.

Consensus analysis was designed to investigate the content of individual's mental models, referred to as 'schema', and the extent to which there is an overlap in content, or 'shared understanding', among a given group of people. Concepts are identified using open-ended interviews or free listing tasks that involve asking interviewees to list items relevant to a given topic, for example, medicinal plants found in a given area. Thereafter, in a second phase a different set of interviewees are asked to sort, rank, or answer yes/no questions to determine the similarity of responses across interviewees or items. Consensus analysis relies on statistical analysis, i.e., factor analysis or cluster analysis, to measure the degree of consensus, or 'shared knowledge', among individuals.

\section{CHALLENGES IN APPLYING THE MENTAL MODEL CONSTRUCT TO NATURAL RESOURCE MANAGEMENT}

The mental model construct has the potential to provide insight into peoples' understanding of natural processes and hence natural resource management. It provides a mechanism that may enhance our ability to understand the motivations for human behavior where other social science constructs, such as attitudes, values, and beliefs, have proved limited. In realizing this potential, a number of research challenges must be addressed.

An initial challenge involves the issue of elicitation, which raises a number of pertinent methodological research questions. What are the relative strengths and weaknesses of direct and indirect mental model elicitation, and particular elicitation and analysis techniques? Do different methods suit different 
contexts and purposes? How well do they overcome the challenge of valid external representation of barely accessible modes of thinking? How successful are they in their own rights, and how much do they depend on the skill of the social scientist conducting and interpreting the elicitation method? To what extent do interpersonal factors, such as trust and honesty, affect the process of elicitation and consequently the external representation of a mental model and its future use? These questions cannot readily be answered from the literature available to date; they are the subject of further research by the authors.

A problem closely tied to this issue of elicitation relates to Argyris and Schon's (1974) 'theories of action'. That is, how do we know whether the elicited mental model represents the interviewee's 'espoused theory' (what they say) or their 'theory in use' (what they do)? The eventual discrepancies between these often explain conflicts observed between mental and, so-called, behavioral models. If mental models are assumed to be the cognitive mechanism upon which reasoning, decision making, and behavior are based, in some cases, depending on the research purpose, it is the 'theoryin-use' version of the mental model in which we are most interested.

If the mental model construct is to be used as a theoretical tool to better understand how people think about and thus interact with natural resource systems, or a practical tool to support collective decision making and action, further research on the relationships between individual and collective mental models is also required.

\section{CONCLUSION}

Using the mental model construct to gain insight into how people conceive, and therefore are inclined to act toward, the world around them is, theoretically speaking, an attractive proposition for natural resource management practitioners. A mental model approach to cognition goes beyond stakeholders' preferences, goals, and values associated with a given resource, to provide a rich picture of how stakeholders perceive natural resource systems to function. This picture can tell us not only what concepts stakeholders' consider important to a given issue, but also how these concepts are organized cognitively and the dynamic interactions between them. It offers some insight into how people comprehend a system, how they believe the system might respond to interventions, and how they might intervene themselves. Similarities and differences in understanding can be compared across time and space to improve overall understanding of a given system and to support collective action.

Theoretical evidence continues to mount within the fields of psychology and cognitive science that people do indeed use mental models to reason and make predictions about the world around them. However, there remain a number of challenges to be able to situate the construct effectively within the NRM domain. One initial challenge is to continue to improve methods of eliciting mental models. Systems of interest in the domain of NRM are complex and dynamic, functioning at a range of temporal and spatial scales. Elicitation techniques therefore need to be capable of incorporating this complexity and they need to be capable of clear and legitimate representation of people's thinking. Although other fields of study, such as systems research and risk communication, have much to offer in this regard, further research is required to assess the relative merits of existing techniques and develop new techniques suited to the NRM field. Actors within the NRM context are typically diverse, coming from a range of socio-cultural backgrounds. Elicitation techniques therefore need to cater to the interpersonal diversity and complexity of actor relationships inherent to the field of NRM. A rich mental models approach in NRM might thus seek to build communication and collaboration across actors by using mental models as a means of mutual understanding (Abel et al. 1998). It would ensure elicitation of mental models in a holistic way, that goes beyond mental models of biophysical and tangible processes to incorporate peoples' understandings of governance, and interactor relationships, including trust and differing values.

Responses to this article can be read online at: http://www.ecologyandsociety.org/voll6/iss 1/art46/ responses/ 


\section{Acknowledgments:}

The lead author would like to acknowledge that this paper has been written as part of the development of her PhD in mental model elicitation techniques, which is kindly funded by the University of Queensland and HEMA Consulting Pty Ltd. We would also like to thank the anonymous reviewers for their insightful comments.

\section{LITERATURE CITED}

Abel, N., H. Ross, and P. Walker. 1998. Mental models in rangeland research, communication and management. Rangeland Journal 20:77-91.

Argyris, C., and D. Schon. 1974. Theory in practice: increasing professional effectiveness. Jossey-Bass, Oxford, UK.

Austin, D. E. 1994. Incorporating cognitive theory into environmental policymaking. The Environmental Professional 16:262-274.

Bainbridge, L. 1991. Mental models and cognitive skill: the example of industrial process operation. Pages 119-144 in A. Rutherford and Y. Rogers, editors. Models in the mind. Academic Press, New York, New York, USA.

Bartlett, F. C. 1932. Remembering: a study in experimental and social psychology. Cambridge University Press, Cambridge, UK.

Biggs, H., D. Du Toit, M. Etienne, N. Jones, A. Leitch, T. Lynam, S. Pollard, and S. Stone-Jovicich. 2008. Preliminary exploration of two approaches to documenting elements of the mental models of stakeholders in the Crocodile Catchment, South Africa. Water Research Commission, Report KV 216/08, South Africa.

Breakwell, G. M. 2001. Mental models and social representations of hazards: the significance of identity processes. Journal of Risk Research 4:341-351.

Brehmer, B. 1992. Dynamic decision making: human control of complex systems. Acta Psychologica 81:211-241.
Brewer, W. F. 1987. Schemas versus mental models in human memory. Pages 187-197 in P. Morris, editor. Modelling cognition. John Wiley \& Sons, Chichester, UK.

Carley, K., and M. Palmquist. 1992. Extracting, representing and analyzing mental models. Social Forces 70:601-635.

Collins, A., and D. Gentner. 1987. How people construct mental models. Pages 243-268 in D. Holland and N. Quinn, editors. Cultural models in language and thought. Cambridge University Press, Cambridge, UK.

Cooke, N. 1999. Knowledge elicitation. Pages 479-509 in F. T. Durso, R. S. Nickerson, S. T. Dumais, S. Lewandowsky, and T. J. Perfect, editors. Handbook of applied cognition. John Wiley \& Sons, Chichester, UK.

Cooke, N., E. Salas, J. A. Cannon-Bowers, and R. Stout. 2000. Measuring team knowledge. Human Factors 42:151-173.

Craik, K. J. W. 1943. The nature of explanation. Cambridge University Press, Cambridge, UK.

D'Andrade, R. 1995. The development of cognitive anthropology. Cambridge University Press, Cambridge, UK.

DiSessa, A. A. 1983. Phenomenology and the evolution of intuition. Pages 15-34 in D. Gentner and A. Stevens, editors. Mental models. Lawrence Erlbaum Associates, Hillsdale, New Jersey, USA.

Doerner, D. 1980. On the difficulties people have in dealing with complexity. Simulation and Gaming 11:87-106.

Dove, J. E., L. A. Everett, and P. F. Preece. 1999. Exploring a hydrological concept through children's drawings. International Journal of Science Education 21:485-497.

Downs, R. M. 1976. Cognitive mapping and information processing: a commentary. Pages 67-70 in G. Moore and R. G. Golledge, editors. Environmental knowing: theories, research and methods. Dowden, Hutchinson and Ross, Stroudsburg, Pennsylvania, USA. 
Doyle, J. K., and D. N. Ford. 1998. Mental models concepts for system dynamics research. System Dynamics Review 14:3-29.

Dray, A., P. Perez, N. Jones, C. Le Page, P. D'Aquino, I. White, and T. Auatabu. 2006. The AtollGame experience: from knowledge engineering to a computer-assisted role playing game. Journal of Artificial Societies and Social Simulation 9:6.

Dray, A., P. Perez, C. Le Page, P. D'Aquino, and I. White. 2007. Who wants to terminate the game? The role of vested interests and meta-players in the AtollGame experience. Simulation and Gaming 38:494-511.

Etienne, M., D. R. Du Toit, and S. Pollard. 2011. ARDI: a co-construction method for participatory modeling in natural resources management. Ecology and Society 16(1):44 [online] URL: http:// www.ecologyandsociety.org/vol16/iss1/art44/.

Gentner, D., and D. R. Gentner. 1983. Flowing waters or teeming crowds: mental models of electricity. Pages 99-130 in D. Gentner and A. Stevens, editors. Mental models. Lawrence Erlbaum, Hillsdale, New Jersey, USA.

Greeno, G. J. 1983. Conceptual entities. Pages 227-252 in D. Gentner and A. Stevens, editors. Mental models. Lawrence Erlbaum, Hillsdale, New Jersey, USA.

Hall, R. I., P. W. Aitchison, and W. L. Kocay. 1994. Causal policy maps of managers: formal methods for elicitation and analysis. Systems Dynamics Review 10:337-360.

Hodgkinson, G. P., A. J. Maule, and N. Brown, J. 2004. Causal cognitive mapping in the organizational strategy field: a comparison of alternative elicitation procedures. Organizational Research Methods 7:3-26.

Holland, J. H., K. J. Holyoak, R. E. Nisbett, and P. $\mathrm{R}$. Thagard. 1986. Induction: processes of inference, learning, and discovery. MIT Press, Cambridge, Massachusetts, USA.

Johnson-Laird, P. N. 1983. Mental models. Cambridge University Press, Cambridge, UK.

Johnson-Laird, P. N. 1989. Mental models. Pages 467-499 in M. I. Posner, editor. Foundations of cognitive science. MIT Press, Cambridge, Massachusetts, USA.

Kearney, A. R., G. Bradley, R. Kaplan, and S. Kaplan. 1999. Stakeholder perspectives on appropriate forest management in the Pacific Northwest. Forest Science 45:62-73.

Kearney, A. R., and S. Kaplan. 1997. Toward a methodology for the measurement of knowledge structures of ordinary people: the conceptual content cognitive map (3CM). Environment and Behavior 29:579-617.

Klayman, J., and Y.-W. Ha. 1989. Hypothesis testing in rule discovery: strategy, structure and content. Journal of Experimental Psychology 5:596-604.

Klimoski, R., and S. Mohammed. 1994. Team mental model: construct or metaphor. Journal of Management 20:403-437.

Kolkman, M. J., M. Kok, and A. van der Veen. 2005. Mental model mapping as a new tool to analyse the use of information in decision-making in integrated water management. Physics and Chemistry of the Earth 30:317-332.

Langan-Fox, J., S. Code, and K. Langfield-Smith. 2000. Team mental models: techniques, methods and analytic approaches. Human Factors 42:242-271.

Langan-Fox, J., A. Wirth, S. Code, K. LangfieldSmith, and A. Wirth. 2001. Analyzing shared and team mental models. International Journal of Industrial Ergonomics 28:99-112.

Larkin, J. H. 1983. The role of problem representation in physics. Pages 75-97 in D. Gentner and A. Stevens, editors. Mental models. Lawrence Erlbaum Associates, Hillsdale, New Jersey, USA.

Lowe, T. D., and I. Lorenzoni. 2007. Danger is all around: eliciting expert perceptions for managing climate change through a mental models approach. Global Environmental Change 17:131-146.

Lynam, T., F. Bousquet, C. Le Page, P. d'Aquino, O. Barreteau, F. Chinembiri, and B. Mombeshora. 2002. Adapting science to adaptive managers: spidergrams, belief models, and multi-agent systems modeling. Conservation Ecology 5(2):24. 
[online] URL: http://www.ecologyandsociety.org/vol5/ iss $2 / \operatorname{art} 24 /$.

Mathevet, R., M. Etienne, T. Lynam, and C. Calvet. 2011. Water management in the Camargue Biosphere Reserve: insights from comparative mental models analysis. Ecology and Society 16 (1):43. [online] URL: http://www.ecologyandsociety. org/vol16/iss 1/art43/

Moore, G. T., and R. G. Golledge. 1976. Environmental knowing: concepts and theories. Pages 3-24 in G. T. Moore and R. G. Golledge, editors. Environmental knowing: theories, research and methods. Dowden Hutchinson and Ross Inc, Stroudsburg, Pennsylvania, USA.

Moray, N. 1998. Identifying mental models of complex human-machine systems. International Journal of Industrial Ergonomics 22:293-297.

Moray, N. 2004. Models of models of...mental models. Pages 506-526 in N. Moray, editor. Ergonomics: major writings. Taylor and Francis, London, UK.

Morgan, M. G., B. Fischhoff, A. Bostrom, and C. Atman, J. 2002. Risk communication: a mental models approach. Cambridge University Press, New York, New York, USA.

Nersessian, N. J. 2002. The cognitive basis of model-based reasoning in science. Pages 133-153 in P. Carruthers, S. Stich, and M. Siegal, editors. The cognitive basis of science. Cambridge University Press, Cambridge, UK.

Osborne, R. J., and M. M. Cosgrove. 1983. Children's conceptions of the changes of the state of water. Journal of Research in Science Teaching 20:825-838.

Ozesmi, U., and S. L. Ozesmi. 2004. Ecological models based on people's knowledge: a multi-step fuzzy cognition mapping approach. Ecological Modelling 176:43-64.

Pahl-Wostl, C., and M. Hare. 2004. Processes of social learning in integrated water management. Journal of Community and Applied Social Psychology 14:193-206.
Quinn, N. 2005. How to reconstruct schemas people share. Pages 33-81 in N. Quinn, editor. Finding culture in talk: a collection of methods. Palgrave Miller, New York, New York, USA.

Rickheit, G., and L. Sichelschmidt. 1999. Mental models: some answers, some questions, some suggestions. Pages 9-40 in G. Rickheit and C. Habel, editors. Mental models in discourse processing and reasoning. Elsevier, Amsterdam, The Netherlands.

Rouse, W. B., and N. M. Morris. 1986. On looking into the black box: prospects and limits in the search for mental models. Psychological Bulletin 100:349-363.

Rutherford, A., and J. R. Wilson. 2004. Models of mental models: an ergonomist-psychologist dialogue. Pages 309-323 in N. Moray, editor. Ergonomics major writings: psychological mechanisms and models in ergonomics. Taylor and Francis, London, UK.

Samarapungavan, A., S. Vosniaudou, and W. F. Brewer. 1996. Mental models of the earth, sun and moon. Cognitive Development 11:491-521.

Sterman, J. D. 1994. Learning in and about complex systems. System Dynamics Review 10:291-330.

Sterman, J. D. 2000. Business dynamics: systems thinking and modeling for a complex world. Irwin McGraw-Hill, Boston, Massachusetts, USA.

Stone-Jovicich, S. S., T. Lynam, A. Leitch, and N. A. Jones. 2011. Using Consensus Analysis to Assess Mental Models about Water Use and Management in the Crocodile River Catchment, South Africa. Ecology and Society 16(1):45. [online] URL: http:/ /www.ecologyandsociety.org/vol16/iss 1/art45/

Strauss, C., and N. Quinn. 1997. A cognitive theory of cultural meaning. Cambridge University Press, Cambridge, UK.

Swan, J., and S. Newell. 1998. Making sense of the technological innovation: the political and social dynamics of cognition. Pages 108-129 in C. Eden and J.-C. Spencer, editors. Managerial and organisational cognition. Sage Publications, London, UK. 
Tikkanen, J., T. Isokaanta, J. Pykalaninen, and P. Leskinen. 2006. Applying cognitive mapping approach to explore the objective-structure of forest owners in a northern Finnish case area. Forest Policy and Economics 9:139-152.

Vosniaudou, S. 1994. Universal and culturespecific properties of children's mental models of the Earth. Pages 412-430 in L. A. Hirschfeld and S. A. Gelman, editors. Mapping the mind: domain specificity in cognition and culture. Cambridge University Press, Cambridge, UK.

Vosniaudou, S., and W. F. Brewer. 1992. Mental models of the earth: a study of conceptual change in childhood. Cognitive Psychology 24:535-585.

Walker, P. A. 1997. Resolving problems with INFLUENCE. Australian Local Government Yearbook 1997:167-168.

Wilson, J. R., and A. Rutherford. 1989. Mental models: theory and application in human factors. Human Factors 31:617-634. 